\title{
Representations of Ageing in the Media
}

\author{
Virpi Ylänne
}

\begin{abstract}
This chapter reviews research on representations of older people and ageing in print and TV media, focusing on advertising. Findings from content analytic studies are summarised and a case is then made for the necessity for more context sensitive research. Media discourses are related to assumptions and aspirations regarding the lifespan and lifestyles at older age: 'positive' portrayals reveal limited depictions of ageing. Representations in advertising provide a rich resource for cultural gerontologists, but these need to be understood as highly context specific cultural constructs that offer versions of the 'reality' of older age for very specific purposes.
\end{abstract}

Key words for index:

media, television, print media, advertising, stereotypes of ageing, representation, content analysis, grey market, active ageing, successful ageing, consumerism, humour and ageing 
Interest in the nature and the possible effects of media portrayals of older adults has been growing in recent years within communication and media studies, as well as in social and cultural gerontology. Inappropriate and inaccurate negative representations are seen to affect negative stereotypic attitudes and expectations about older people among younger and older consumers alike (Gerbner 1998, Mares and Cantor 1992), potentially lowering older people's self-esteem (Harwood 1997). Positive and more diverse images are regarded as desirable, especially for older media users, in supporting positive self identity. In the twenty-first century, the visibility of older people and their positive portrayal in the media, including advertising, have - arguably - increased. But media and advertising depictions about ageing and older age continue to be somewhat limited. In particular, what might be considered 'positive' portrayals can turn out to be more ambiguous in their constructions of older age than might at first appear.

This chapter will review recent research on representations of older people in print and TV media, focusing mainly on advertising. Firstly, some findings from content analytic studies will be summarised and evaluated for their interpretative rigour. Secondly, some differences between advertising targeted at the 'grey/silver market' vis-à-vis other consumer groups will be considered. Some examples of qualitative studies on advertising and media imagery will then be given. Lastly we will consider salient discourses of ageing in the (advertising) media, and how these relate to cultural gerontological concerns.

\section{Content analytic research on older people in the media}

There is a steadily growing body of work, especially in the US but also globally, about how older people are portrayed on prime-time television (for example Harwood and Giles 1992, Kessler, Rakoczy and Staudinger 2004, Kessler, Schwender and Bowen 2010), films (for example Bazzini et al. 1997, Lauzen and Dozier 2005, Robinson et al. 2007), documentaries (Robinson, Skill and Turner 2004), as well as in theatre, dance and film (for example Barnes Lipscomb and Marshall 2010, Gullette 2004). Research on advertising has looked at print media (for example Carrigan and Szmigin 1999, Miller et al. 1999, Robinson, Gustafson and Popovich 2008, Williams, Ylänne and Wadleigh 2007, Williams, Wadleigh and Ylänne 2010) and television 
advertising (for example Chen and Ylänne 2012, Prieler 2012, Prieler et al. 2011, Simcock and Sudbury 2006), or both (for example Zhang et al. 2006). Research on media and advertising portrayals of older people has typically adopted content analysis as a method, and the chapter now summarises some of these findings.

\section{Presence}

Content analyses of media representations of older people record frequencies of occurrence of such characters in a sample of representative data of, for example, print or TV adverts. These are coded for categories such as gender, role prominence (major/minor/background), setting (home/work/outdoors and so on), tone (positive/negative/neutral) and the product advertised, among others. Generally speaking, research from North America and Europe reports that older people (typically defined as those over 50 years) are under-represented in the media (including advertising) relative to their respective proportion of the population (for example Roy and Harwood 1997, Simcock and Sudbury 2006). Under-representation has been found to be particularly pertinent in relation to people over 65 (for example Kessler et al. 2004). As regards advertising, Prieler, Kohlbacher and colleagues report under-representation in Asian contexts, too, in TV adverts in Japan and South Korea. For example, 6.1percent of TV adverts in Japan (in 2007) included people over 65, whereas they comprised 20.2 percent of the actual population (Prieler 2012: 59). Less prevalent under-representation was reported of older people in China (Zhan, Song and Carver 2008). In Japanese TV adverts, older people, but especially older females, were under-represented, echoing findings in Western contexts. In sum, evidence of old age discrimination in the media and specifically in advertising is manifested in the absence of senior characters in a variety of contexts.

\section{Prominence}

Presence (or absence) alone does not fully describe how prominent older characters are in the media, though. That is why the status of the roles older characters play has been examined, too. Some contrasting findings have emerged. It has however been suggested that where older people do appear in print or TV adverts, they tend to be cast in roles that indicate their use in indexing specific qualities of the product (such 
as reliability) or the company (such as its long history) (for example Swayne and Greco 1987, Williams et al. 2010). These are likely to be age-marked roles and contexts (for example Miller, Leyell and Mazachek 2004). In other words, older adults in adverts are often chosen for specific purposes, rather than just to represent 'people'.

\section{Positivity / negativity}

Beyond presence and role prominence, older characters in the media have been coded in terms of positive or negative portrayal, with negative depictions predominating in the past. However, in advertising more specifically, despite under-representation, positive portrayals of older adults are reported as more salient (for example Roy and Harwood 1997). One reason for this may be the importance of positivity in advertising in general, since positive associations with the product need to be enforced. However, the rationale for coding an older character as 'positively' portrayed is not always clear in content analytic studies.

\section{Products}

As regards products, older people tend to appear in adverts for certain types of products rather than others, reflecting stereotypical expectations about behaviour and characteristics linked with older people as a social group. Older adults advertising food, pharmaceutical products, health aids and financial / insurance products and services have been found to be the most prevalent categories in both Western and Eastern contexts (Williams et al. 2010, Prieler 2012).

\section{Beyond content analysis}

In content analytic studies images are broken down into components and portrayals are divided into a set of discrete categories and trait-like dimensions. Thus we learn that older people are portrayed positively/negatively, as healthy, or humorously and so on, and how often this happens in a particular context. We are to assume that frequency relates to importance or even impact on viewers/readers. While this method has been effective in describing general trends and patterns, the contextual 
complexity of the depictions is arguably lost. The result is rather a-contextual lists about the nature of portrayals, but with little indication of the connections between the items. We therefore have no clear understanding about older people as portrayed for example in relation to different types of positive and negative characters in specific contexts.

To deepen our understanding of portrayals of older people in advertising we can analyse images according to more complex stereotypical categories in order to know what kinds of stereotypes are being used. This was done by Miller, Leyell and Mazachek (2004), who used stereotypes classified by Hummert and colleagues (1994) to examine portrayals on TV adverts. The most commonly depicted stereotype they found was that of 'adventurous' Golden Ager, followed by the Perfect Grandparent and the Productive Golden Ager (in Hummert and colleagues' taxonomy, these are positive stereotypes held by people of all ages: the 'Perfect Grandparent' is kind, loving and family oriented, and the 'Golden Ager' lively, adventurous and alert). Although this research helps to elaborate our understanding of these portrayals, Miller and colleagues' use of Hummert's stereotypes applies a coding system that is given 'a-priori' from a source not originally developed in an advertising context. Research carried out by Williams and colleagues (2010), in contrast, sought to devise a typology that emerged from advertising materials (UK magazine adverts) themselves. The six types were labelled as: Golden-Ager; Perfect Grandparent; 'Legacy'/ 'Mentor' themes; Coper; Comedic and Celebrity Endorser.

The label 'Golden-Ager' described older people portrayed as full of zest, often having glamorous and luxurious lifestyles, in other words, prototypical media representations of 'third agers'. 'Perfect Grandparents' were shown with grandchildren, sometimes depicting several generations, often in close-ups of smiling, happy families. 'Legacy' themes referred to older persons depicted with 'gravitas' and status, typically in mentor roles with implied experience and wisdom (and these tended to be older men). 'The Coper', on the other hand, had a problem - such as a (minor) disability - but was coping with it because of the product being sold, and 'Comedic' older people were those depicted in humorous situations. 'Celebrity Endorsers' were well known older adults in the public eye who endorsed products, typically acting as positive role models. These categories were largely confirmed by audience research with 
respondents across age groups. We cannot correlate these types of portrayals with positive / negative images in a straightforward way, although negative depictions mostly linked with the 'Coper' type, and positive depictions with all the others, with the 'Comedic' category being more ambiguous. In order to evaluate the representations and their potential effects, it is also important to consider other contextual factors, such as the target audience of the adverts. We will now move on to discussing one such study.

\section{Effects of advertising targets}

Williams, Ylänne, Wadleigh and Chen (2010) investigated UK magazine adverts depicting older adults, comparing adverts in Saga Magazine (a glossy, subscriptiononly high circulation magazine for the 50+ audience) with those appearing in ten general readership magazines. The main differences were the frequency of adverts containing (an) older model(s), their prominence as central characters and product categories.

Predictably, Saga contained by far the most such adverts by number, although older people featured as central (as opposed to secondary or peripheral) characters most often in all the magazines (including Saga). 'Golden Ager' was the most frequent type of portrayal in both Saga and other magazines, followed by 'Coper' and 'Perfect Grandparent' in Saga but 'Mentor' and 'Comedic' in other magazines. Older adults were most commonly used in adverts for help/support and medical/health products in Saga, but for food and drink, followed by entertainment and technological products in other publications. Adverts in Saga were less likely to feature older people in humorous situations and more likely to feature them in home and family as opposed to outdoor settings, as was the case in the other magazines.

These observations were linked to the products advertised and their target audiences. Over 60 percent of all the adverts were aimed at older consumers in some way (coded as 'age exclusive') and, predictably, the vast majority of these appeared in Saga. It was mainly in general readership magazines that older protagonists featured 'incidentally' and not just as 'tokens' of age as is often the case in advertising, where older adults index longevity or experience, for example. In these magazines, 'age 
contrastive' adverts, which distanced the older character from the audience, also appeared (and some of these accounted for the humorous depictions). 'Age-targeted' advertising is a somewhat fuzzy concept, though, as some Saga readers might not self-identify with the imagery in adverts for help and support aids, for example, but instead align as potential buyers of such goods for older family members. In general, the adverts in Saga can, however, provide opportunities for in-group identification for older readers. Media and advertising portrayals are one resource for ageing individuals to learn what it is like to be old.

\section{Discourses and images of ageing in the media}

\section{Third Age publications}

In the UK, magazines such as Yours, Choice and Saga Magazine have, for some time, proclaimed as their mission to counter-influence negative stereotypes of older age. They present editorial and advertising content that fosters a positive self-image and a healthier and more dynamic lifestyle for older persons (Bytheway 2003, Featherstone and Hepworth 1995). Featherstone and Hepworth's (1995) longitudinal (1972-1993) case study of the Choice magazine (formerly Retirement Choice) is a good example of the emergence of (post)modern notions of successful ageing, dominated by images of middle-aged and older adults looking relatively glamorous, healthy, youthful, and indeed to an extent 'ageless'. However, as Featherstone and Hepworth pointed out, the emphasis in the magazine on a lifestyle based on consumerism is out of financial reach for many older people, and there is little engagement with the problems of later life that are still an everyday reality for many. At the same time, the primary 'third age' target audience and the aspirational function of the magazine(s) need to be taken into account in analyses and critique of these media, since the 'reality' they present is heavily mediated and also driven by advertising agendas to appeal to a specific demographic. Such publications exemplify 'the commercialized retirement culture' (Katz 2013: 36) that has become widespread.

Mediated constructions of successful ageing were also examined in a more recent study by Lumme-Sandt (2011), who examined images of ageing in a Finnish 50+ magazine $(E T)$, focussing on their potential influence on individuals' self-perception. 
Three dominant discourses emerged in the human interest articles: freedom from work and predetermined roles, including possibilities for new identities; activity, which, besides physical activity, also included retaining mental agility and curiosity into older age; and looking good/taking care of one's appearance, which in more recent (2006) issues also included praise for 'graceful' ageing, and not emulating youth. These themes which promote activity and self-care are echoed in much third age marketing more globally (Katz 2005, Chen and Ylänne 2012). Lumme-Sandt and Uotila (2012) also comment on the coverage (in ET) of love and intimate relationships at older age, which is emerging as a notable theme, albeit in a frame that is limited in that it tends to construct the maintenance of intimate relationships (see also Marshall 2010) and successful coupledom as markers of successful ageing.

\section{Advertising}

Ageing well and health issues are frequent themes in advertising for older cohorts. Ylänne, Williams and Wadleigh (2009), in their examination of adverts with a health and well-being focus, depicting older adults (in a cross section of UK magazines), found an underlying assumption of decline with age as well as risk in the data. Prominent themes in the adverts, achieved via linguistic and semiotic means, included the maintenance of independence and quality of life; managing risks; staying healthy and active; taking pride in appearance; and discourses of responsibility and choice. Advertising frequently draws on associations between increasing age and health concerns (and this partly accounts for older adults appearing in such adverts) and these adverts emphasise the need to take control of one's health as an ageing person. In this respect, the discourses echo those found in anti-ageing adverts which in addition to idealising youth and presenting old age as disease, also promise control and even 'cure' for ageing and its associated physical and visible signs (Calasanti, Sorensen and King 2012).

The body and body work (and beauty work) has acquired a central position in the representations and discourses of ageing. Successful ageing is equated with active ageing which is positively presented as the aspirational ideal of ageing well, especially in media and advertising targeting the over 50s. This can be interpreted as a type of age denial, potentially creating a binary opposition between successfully and 
unsuccessfully ageing bodies. Gilleard and Higgs (2013: 166) propose, however, that '[i]n being minded to bother about one's body, individuals can feel that their body still matters'. The 'new ageing', Gilleard and Higgs suggest, entails not so much clinging onto youth, but wishing to retain coherence in one's identity, life narrative and everyday practices by a 'generation that has learned to privilege choice, autonomy, self-expression and pleasure' (ibid.). Diachronic coherence is undoubtedly important for ageing selves, but the ideology of resisting change seems ubiquitous in mediated representations of ageing.

Besides looking at the ideologies, discourses and images of ageing that can be identified in adverts (and media more generally), cultural gerontologists might also profitably investigate how and for what purposes older adults feature in specific advertising campaigns. An example of a recent qualitative study by Yoon and Powell (2012) focused on two campaigns by leading UK stores, Tesco (supermarket) and Marks \& Spencer (M\&S; major high street retailer), featuring older celebrities. Tesco’s 'Dotty campaign' (1995-2005) featured an 'ever-challenging, difficult, demanding, interfering, annoying, bossy and fanatical' (Yoon and Powell 2012: 1329) older female character played by the British actor, Prunella Scales. The campaign helped improve the company's fortunes in the 1990s and construct an image of a helpful, proactive supermarket, even in the face of the most demanding customer, embodied in 'Dotty'. This was an example of a celebrity acting a part based on an 'invented' character, who had a broad audience appeal, but who nevertheless functioned as 'perpetuating and reinforcing the negative stereotyping of older people' (ibid.) - especially women - and drawing on the popular negative mother-in-law theme (which, in the UK context, comprises demanding and somewhat cantankerous qualities) in the story-line.

M\&S, on the other hand, have (since 2005) reaped the benefits of the 'Twiggy effect', featuring the older female model Twiggy as a celebrity endorser in their advertising, and providing babyboomers with a potential 'projective identification' (Yoon and Powell 2012: 1330) with someone they would have recognised since her supermodel days in the 1960s. '[L]ocating Twiggy within a group of younger models ... taps into the recognition that one can aspire to look one's best irrespective of age', positioning 'consumption as a process' (1329-1330) across the lifespan. The appeal, especially to 
older females, relies on Twiggy not standing out as an 'other'. Whereas the Tesco campaign used a traditional, negative stereotype of an older woman that consumers at large recognised, the $M \& S$ campaign provided aspirational images of a celebrity. A qualitative approach to data highlights different types of portrayal and the ways in which specific campaigns use older models in ways that go beyond the categorisations used in simple content analysis approach.

\section{Humour}

Humour contributes to the regulation of social norms and the status of social groups relative to one another, making an examination of humorous media advertising portrayals of older people worth-while. Williams (unpublished) investigated over 300 such UK TV adverts (from 2000s) and these revealed a variety of depictions. 'Cheeky, fun and playful' older characters were portrayed engaging in light hearted teasing of others, often in intergenerational (family) contexts, and they had the upper hand, constituting 'superiority humour'. 'Incongruity humour' arose from a humorous violation of expectations which followed the setting up - semiotically and behaviourally - of an extreme stereotype of an older person (such as a 'little old lady'). Denigratory humour confirmed negative expectations about older people, such as their 'grumpiness' or declining cognitive abilities. This emerged as a predominant theme in these adverts. Lastly, mocking humour, a more extreme ridiculing, was typically found in adverts targeting a young (especially male) audience (see also Miller et al. 2004). These sometimes featured repulsive and disgusting imagery, designed to shock (young) viewers and to distance themselves from the older characters. Whilst viewers are invited to laugh with the older characters in the first type of portrayal, the others typically evoke laughing at them. The relationship between humour and positive/negative stereotyping can be ambiguous, however, especially as the multimodal medium of TV adverts enables humour to be achieved by a variety of means (such as sound, image, language). Although we can laugh at extreme stereotypes in adverts as being out-dated and inaccurate ('laughable'), it seems advertisers in the twenty-first century have not altogether abandoned the use of humorous negative, ageist, caricatures when it comes to older people (see also Low and Dupuis-Blanchard 2013), so that these can still provide categories for interpreting older age (especially in publications targeting younger consumers). 


\section{Conclusion}

Despite global population ageing, older people are still under-represented in media and advertising contexts. Furthermore, their representations are limited in terms of the roles they occupy, the products they advertise and the stereotypes that are evoked in the representations. Older characters often index qualities such as experience, longevity and traditional family values. These roles are likely to have positive connotations. But especially in adverts targeting younger audiences, older adults can appear as targets of ridicule or as extreme caricatures that rely on negative associations with ageing, 'othering' older people. Third age marketing, on the other hand, provides aspirational images of successful ageing tied up with consumerist lifestyles. Although the imagery of active and healthy 'golden agers' appears positive, it also promotes idealistic notions of individual agency in the management of the ageing process. Negative imagery also works to this end in highlighting age-related risks as problems for which solutions are provided. Variation in ageing successfully or in lifestyles is not promoted in advertising.

Fifty plus marketing and its representations of older adults has to be interpreted in a socio-historical context, taking into account cohort effects. These, together with general aims of advertising and older adults' reported self perception of lower subjective and cognitive age than chronological age (and advertisers' assumption of this), go some way in accounting for the under-representation, especially of people over 65 , in advertising. So although representations of older people in advertising and media more generally can provide a rich resource for cultural gerontology, the images therein are highly context specific cultural constructs that offer versions of older age for very specific purposes.

\section{References}

Barnes Lipscomb, V. and Marshall, L. (eds) (2010) Staging Age: The Performance of Age in Theatre, Dance, and Film. New York: Palgrave Macmillan. 
Bazzini, D. G., McIntosh, W. D., Smith, S M., Cook, S. and Harris, C. (1997) The aging woman in popular film: Under-represented, unattractive, unfriendly, and unintelligent. Sex Roles 36: 531-543.

Bytheway, B. (2003) Visual representations of late life. In C. A. Faircloth (ed.) Aging Bodies. Images and Everyday Experience. Walnut Creek, Cal.: Altamira Press, 29-53.

Calasanti, T., Sorensen, A. and King, N. (2012) Anti-ageing advertisements and perceptions of ageing. In V. Ylänne (ed.) Representing Ageing. Images and Identities. Basingstoke: Palgrave Macmillan, 19-35.

Carrigan, M. and Szmigin, I. (1999) Model-audience relevance in contemporary advertising: Targeting the cognitively young. Marketing and Research Today 28(1): $1-9$.

Chen,C.-H. and Ylänne, V. (2012) Consumerism v. constructing older age: A case study of over fifties life insurance TV advertising In V. Ylänne (ed.), 36-52.

Featherstone, M. and Hepworth, M. (1995) Images of positive ageing: A case study of Retirement Choice magazine. In M. Featherstone and A. Wernick (eds) Images of Ageing. Cultural Representations of Later Life. London: Routledge, 29-47.

Gerbner, G. (1998) Cultivation analysis: An overview. Mass Communication and Society 1(3/4): 175-194.

Gilleard, C. and Higgs, P. (2013) Ageing, Corporeality and Embodiment. London: Anthem Press.

Gullette, M. M. (2004) Aged by Culture. Chicago and London: University of Chicago Press.

Harwood, J. (1997) Viewing age: Lifespan identity and television viewing choices. Journal of Broadcasting and Electronic Media 41: 203-213.

Harwood, J. and Giles, H. (1992) 'Don't make me laugh': Age representations in a humorous context. Discourse and Society 3(3): 403-436. 
Hummert, M. L., Garstka, T., Shaner, J. L. and Strahm, S. (1994) Stereotypes of the elderly held by young, middle-aged and elderly adults. Journal of Gerontology: Psychological Sciences 49: 240-249.

Katz, S. (2005) Cultural Aging. Life Course, Lifestyle, and Senior Worlds. Peterborough, ON: Broadview.

Katz, S. (2013) Active and successful aging. Lifestyle as a gerontological idea. Recherches sociologiques et anthropologiques (online) 44(1): 33-49. http://rsa.revues.org/910 (accessed 22.10.2013).

Kessler, E.-M., Rakoczy, K. and Staudinger, U. M. (2004) The portrayal of older people in prime time television series: The match with gerontological evidence. Ageing and Society 24: 531-552.

Kessler, E.-M., Schwender, C. and Bowen, C. E. (2010) The portrayal of older people's social participation on German prime-time TV advertisements. Journal of Gerontology: Social Sciences 65B(1): 97-106.

Lauzen, M. M. and Dozier, D. M. (2005) Maintaining the double standard: Portrayals of age and gender in popular films. Sex Roles 52:437-446.

Low, J. and Dupuis-Blanchard, S. (2013) From Zoomers to Geezerade: Representations of the aging body in ageist and consumerist society. Societies 3: $52-$ 65.

Lumme-Sandt, K. (2011) Images of ageing in a 50+ magazine. Journal of Aging Studies 25: 45-51.

Lumme-Sandt, K. and Uotila, H. (2012) Talk about love and intimate relationships in a Finnish 50+ magazine. In V. Ylänne (ed.), 68-83.

Mares, M.-L. and Cantor, J. (1992) Elderly viewers' responses to televised portrayals of old age: Empathy and mood management versus social comparison. Communication Research 19(4): 459-478. 
Marshall, B. (2010) Science, medicine and virility surveillance: 'Sexy seniors' in the pharmaceutical imagination. Sociology of Health and Illness 32(2): 211-224.

Miller, D. W., Leyell, T. S. and Mazachek, J. (2004) Stereotypes of the elderly in U.S. television commercials from the 1950s to the 1990s. International Journal of Aging and Human Development 58(4): 315-340.

Miller, P. N., Miller, D. W., McKibbin, E. M., and Pettys, G. L. (1999) Stereotypes of the elderly in magazine advertisements 1956-1996. International Journal of Aging and Human Development 49(4): 319-337.

Prieler, M. (2012) Social groups in South Korean television advertising: Foreigners and older people. Keio Communication Review 34: 57-78.

Prieler, M., Kohlbacher, F., Hagiwara, S. and Arima, A. (2011) Gender representation of older people in Japanese television advertisements. Sex Roles 64: 405-415.

Robinson, J. D., Skill, T. and Turner, J. W. (2004) Media usage patterns and portrayals of seniors. In J.F. Nussbaum and J. Coupland (eds) Handbook of Communication and Aging Research. Mahwah, N.J.: Lawrence Erlbaum, 423-446.

Robinson, T., Callister, M., Magoffin, D. and Moore, J. (2007) The portrayal of older characters in Disney animated films. Journal of Aging Studies 21: 203-213.

Robinson, T., Gustafson, B. and Popovich, M. (2008) Perceptions of negative stereotypes of older people in magazine advertisements: Comparing the perceptions of older adults and college students. Ageing and Society 28: 233-251.

Roy, A. and Harwood, J. (1997) Underrepresented, positively portrayed. Older adults in television commercials. Journal of Applied Communication Research 25: 39-56.

Simcock, P. and Sudbury, L. (2006) The invisible majority? Older models in UK television advertising. International Journal of Advertising 25: 87-106.

Swayne, L.E. and Greco, A.J. (1987) The portrayal of older Americans in television commercials. Journal of Advertising 16: 47-54. 
Williams, A. (unpub.) 'You're having a laugh!': Stereotypes and humour in portrayals of older people in British television advertisements. Unpublished ms., Cardiff University, Wales, UK.

Williams, A., Wadleigh, P. M. and Ylänne, V. (2010) Images of older people in UK magazine advertising: Toward a typology. International Journal of Aging and Human Development 71(2): 83-114.

Williams, A., Ylänne, V. and Wadleigh, P. M. (2007) Selling the 'elixir of life': Images of the elderly in an Olivio advertising campaign. Journal of Aging Studies 21(1): 1-21.

Williams, A., Ylänne, V., Wadleigh, P. M. and Chen, C.-H. (2010) Portrayals of older adults in UK magazine advertisements: Relevance of target audience.

Communications: The European Journal of Communication Research 35(1): 1-27.

Ylänne, V., Williams, A. and Wadleigh, P. M. (2009) Ageing well? Older people's health and well being as portrayed in UK magazine advertisements. International Journal of Ageing and Later Life 4(2): 33-62.

Yoon, H. and Powell, H. (2012) Older consumers and celebrity advertising. Ageing and Society 32(8): 1319-1336.

Zhang, Y.B., Harwood, J., Williams, A., Ylänne-McEwen, V., Wadleigh, P. and Thimm, C. (2006) Older adults in advertising: Multi-national perspectives. Journal of Language and Social Psychology 25(3): 264-282.

Zhang, Y. B., Song, Y. and Carver, L. J. (2008) Cultural values and aging in Chinese television commercials. Journal of Asian Pacific Communication 18(2): 209-224. 